\title{
Loss or duplication of key regulatory genes coincides with environmental adaptation of the stomatal complex in Nymphaea colorata and Kalanchoe laxiflora
}

\author{
Meizhi $\mathrm{Xu}^{1}$, Fei Chen ${ }^{2}$, Shilian $\mathrm{Qi}^{1}$, Liangsheng Zhang ${ }^{1,2}$ and Shuang $\mathrm{Wu}^{1}$
}

\begin{abstract}
The stomatal complex is critical for gas and water exchange between plants and the atmosphere. Originating over 400 million years ago, the structure of the stomata has evolved to facilitate the adaptation of plants to various environments. Although the molecular mechanism of stomatal development in Arabidopsis has been widely studied, the evolution of stomatal structure and its molecular regulators in different species remains to be answered. In this study, we examined stomatal development and the orthologues of Arabidopsis stomatal genes in a basal angiosperm plant, Nymphaea colorata, and a member of the eudicot CAM family, Kalanchoe laxiflora, which represent the adaptation to aquatic and drought environments, respectively. Our results showed that despite the conservation of core stomatal regulators, a number of critical genes were lost in the N. colorata genome, including EPF2, MPK6, and AP2C3 and the polarity regulators BASL and POLAR. Interestingly, this is coincident with the loss of asymmetric divisions during the stomatal development of $\mathrm{N}$. colorata. In addition, we found that the guard cell in K. laxiflora is surrounded by three or four small subsidiary cells in adaxial leaf surfaces. This type of stomatal complex is formed via repeated asymmetric cell divisions and cell state transitions. This may result from the doubled or quadrupled key genes controlling stomatal development in K. laxiflora. Our results show that loss or duplication of key regulatory genes is associated with environmental adaptation of the stomatal complex.
\end{abstract}

\section{Introduction}

Stomata are a pore-like structure in multiple organs, including leaves and stems, which facilitates gas and water exchange. When environmental conditions are unfavourable, plants can regulate water evapotranspiration and reduce $\mathrm{CO}_{2}$ uptake by opening and closing the stomata. For instance, Crassulacean acid metabolism (CAM) plants are adapted to arid conditions ${ }^{1}$. The stomata in

\footnotetext{
Correspondence: Shuang Wu (wus@fafu.edu.cn)

${ }^{1}$ College of Horticulture, FAFU-UCR Joint Center and Fujian Provincial Key Laboratory of Haixia Applied Plant Systems Biology, Fujian Agriculture and Forestry University, Fuzhou, China

${ }^{2}$ State Key Laboratory of Ecological Pest Control for Fujian and Taiwan Crops: Key Laboratory of Ministry of Education for Genetics, Breeding and Multiple Utilization of Crops, Fujian Agriculture and Forestry University, Fuzhou, China These authors are contributed equally: Meizhi Xu, Fei Chen
}

CAM plants remain closed during the day to reduce evapotranspiration while staying open at night to absorb $\mathrm{CO}_{2}$. These physiological traits make CAM plants resistant to diverse stresses, including strong irradiance and drought $^{2}$.

Stomatal structure is highly conserved across land plants. The basic core structure with two guard cells surrounding the stomatal pore has remained unchanged during evolution ${ }^{3}$. However, the patterning of the mature stomatal structure differs among plant groups and can be generally summarized by three classes: anomocytic, stephanocytic, and paracytic ${ }^{4}$. The widely used model plant Arabidopsis thaliana exhibits anomocytic stomata. However, there are a few species (for example, CAM families) among the eudicots with paracytic stomata ${ }^{5}$.

\section{(c) The Author(s) 2018}

(c) Open Access This article is licensed under a Creative Commons Attribution 4.0 International License, which permits use, sharing, adaptation, distribution and reproduction c. in any medium or format, as long as you give appropriate credit to the original author(s) and the source, provide a link to the Creative Commons license, and indicate if changes were made. The images or other third party material in this article are included in the article's Creative Commons license, unless indicated otherwise in a credit line to the material. If material is not included in the article's Creative Commons license and your intended use is not permitted by statutory regulation or exceeds the permitted use, you will need to obtain permission directly from the copyright holder. To view a copy of this license, visit http://creativecommons.org/licenses/by/4.0/. 
Most grass species have paracytic mature stomata ${ }^{6}$. Amborella trichopoda in ANITA possesses stephanocytic stomata ${ }^{7}$. The diverse architecture of mature stomatal structures may suggest the evolution of their different developmental regulations and their adaption to different environments.

In A. thaliana, meristem mother cells (MMCs) undergo up to three asymmetrical divisions to form guard mother cells (GMCs). In grasses, meristemoids divide asymmetrically to form GMCs, and the lateral neighbouring axial cell lineage surrounding the GMC undergoes asymmetric division to give rise to lateral subsidiary cells (LSCs) ${ }^{8}$. In A. trichopoda, however, protodermal cells can directly become GMCs or divide asymmetrically to produce a $\mathrm{GMC}^{9}$. Hence, the regulation of stomatal development is highly diverse in different groups of land plants.

In the past, A. thaliana and Oryza sativa were often used as model systems to study stomatal patterning and development. Based on those studies, we now have a good understanding of the basic molecular network behind stomatal development. In A. thaliana, a complex signalling cascade of several genes has been identified to promote stomatal development. The secreted peptides of the EPIDERMAL PATTERNING FACTOR (EPF)/EPF-LIKE (EPFL) family act with a mitogen-activated protein kinase (MAPK) cascade to regulate the activity of basic-helixloop-helix (bHLH) transcription factors ${ }^{10}$. EPF1 and EPF2 specifically bind to leucine-rich repeat receptor (LRR) kinase complexes that include members of TOO MANY MOUTHS receptor-like protein (TMM) and the ERECTA family (ER). EPF1 is expressed in late-stage meristemoids, GMCs and young guard cells, whereas EPF2 is expressed in early-stage protodermal cells ${ }^{11,12}$. In the downstream pathway, a number of mitogen-activated protein (MAP) kinases, including MAPKKK YODA, MPKK4/5, MPKK7/9, and MAPK MPK3/6, were found to transduce the signalling for stomatal development ${ }^{13}$. Five bHLH transcription factors positively regulate the stomatal-lineage transition and differentiation. For example, SPEECHLESS (SPCH), MUTE, and FAMA act sequentially to promote the cellular transition in a stagespecific manner. SPCH regulates asymmetric divisions in MMC and MUTE involved in GMC differentiation ${ }^{14,15}$. FAMA promotes the last step to form $\mathrm{GCs}^{16}$. Two additional bHLH proteins, SCREAM/ICE1 and SCREAM2, act redundantly to heterodimerize SPCH, MUTE, and FAMA to coordinate the regulation ${ }^{17}$.

Polarity information is critical in stomatal development and directs asymmetric cell division and possibly cell fate determination. In $A$. thaliana, two unique polarity proteins, POLAR LOCALIZATION DURING ASYMMETRIC DIVISION AND REDISTRIBUTION (POLAR) and BREAKING OF ASYMMETRY IN THE STOMATAL LINEAGE (BASL), show mostly overlapping localization during asymmetric stomatal divisions ${ }^{18,19}$. In the grass, the asymmetric division taking place in the lateral neighbouring cell to produce the subsidiary cell relies on two LRR receptor-like kinases, PANGLOSS1 (PAN1) and PAN2 $2^{20,21}$. PAN proteins are located at the poles in SMCs at the site of contact with GMCs, which precedes the polar accumulation of small GTPases (ROPs) and $\mathrm{F}$-actin ${ }^{22}$. Interestingly, recent observations in Brachypodium distachyon found that BdMUTE regulates subsidiary cells through cell-to-cell movement ${ }^{23}$. In contrast, the MUTE homologue in A. thaliana is immobile $^{23,24}$.

Although stomata morphologies across land plants have been widely examined, questions on the early evolution of angiosperms and the adaptation of stomata to diverse environments remain to be answered. It is not clear how molecular regulation of stomatal development evolved and how that relates to the diverse stomata morphologies among the land plants. Immediately above the root node of angiosperm evolution is the ANITA grade (basal angiosperms), which includes Amborella, Nymphaeales, Illiciaceae, Trimeniaceae and Austrobaileyaceae ${ }^{7}$. In this study, we took advantage of the newly sequenced genome of Nymphaea colorata (not released yet), a typical base angiosperm, to examine stomata regulation in early angiosperm evolution.

The structure and function of stomata are important for environmental adaptation. In some species, stomata underwent radical modifications to facilitate habituation to a particular environment. A recent study indicated that $Z$. marina lost all the genes involved in stomatal differentiation, which is coincident with its marine habituation. Nymphaea colorata is also an aquatic plant, so it is interesting to know if its stomata-related genes also changed during evolution. By contrast, Kalanchoe laxiflora, a CAM species, has adapted to drought conditions and has evolved specialized stomata functions. To understand how the evolution of the molecular regulation of stomatal development is associated with environmental adaptation, we analysed stomatal morphologies and related regulatory cascades in both Nymphaea colorata and $K$. laxiflora. Our analysis showed that although generally conserved, loss or duplication of key genes could be associated with structural and physiological renovations required for individual adaptation of plants to local environments.

\section{Materials and methods}

\section{Plant materials and growth condition}

A. thaliana Columbia seeds were germinated and grown on $1 / 2$ MS medium with $1 \%$ agar, $1 \%$ sucrose and $0.05 \%$ (wt/vol) morpholinoethansulfonic acid monohydrate $(\mathrm{pH}$ 5.7) under a $16 / 8$-h light/dark cycle at $23^{\circ} \mathrm{C}$. Plants were imaged 3-4 days after planting. O. sativa and K. laxiflora 
were grown at $28^{\circ} \mathrm{C}$ with a $16 / 8$-h light/dark photoperiod. $N$. colorata were cultivated in water at $23{ }^{\circ} \mathrm{C}$ in the greenhouse. Leaves of Spirodela polyrhiza were collected in winter 2017 at the Fujian Agriculture and Forestry University.

\section{Methods}

\section{Microscopy and image processing}

For Differential Interference Contrast (DIC) imaging, the protocol was modified slightly according to Raissig et $\mathrm{al}^{23,25}$. Samples from the mid-regions of leaves were cut into small squares and cleared using a solution (ethanol: acetic acid glacial, in proportions $4: 1$ by volume) to remove chlorophyll; then, samples were subjected to a basic solution (a mixture of $7 \% \mathrm{NaOH}$ in $60 \%$ ethanol). Finally, samples were washed briefly with $40 \%$ ethanol and mounted in water for visualization and microscopy analysis. Samples were examined using a Nikon ECLIPSE $\mathrm{Ni}-\mathrm{U}$ microscope fitted with a Nikon DS-Ri 2 digital camera. Images were processed using ImageJ.

\section{Phylogenetic analysis}

We surveyed a number of genomes, such as A. thaliana, K. laxiflora, Sorghum bicolor, O. sativa, Zea mays, Ananas comosus, S. polyrhiza, and A. trichopoda, from Phytozome v12. Nelumbo nucifera and Phalaenopsis equestris were retrieved from ftp://ftp.ncbi.nih.gov/genomes/. Ginkgo biloba was found from GigaDB (http://gigadb.org/). N. colorata was recently sequenced by Liangsheng Zhang's Lab in Fujian Agriculture and Forestry University, and sequences were available in the water lily genome database (eplant.org). To obtain probable orthologous genes, we performed BLASTp (protein query-proteins database) and tBLASTn (protein query-nucleic acid database)
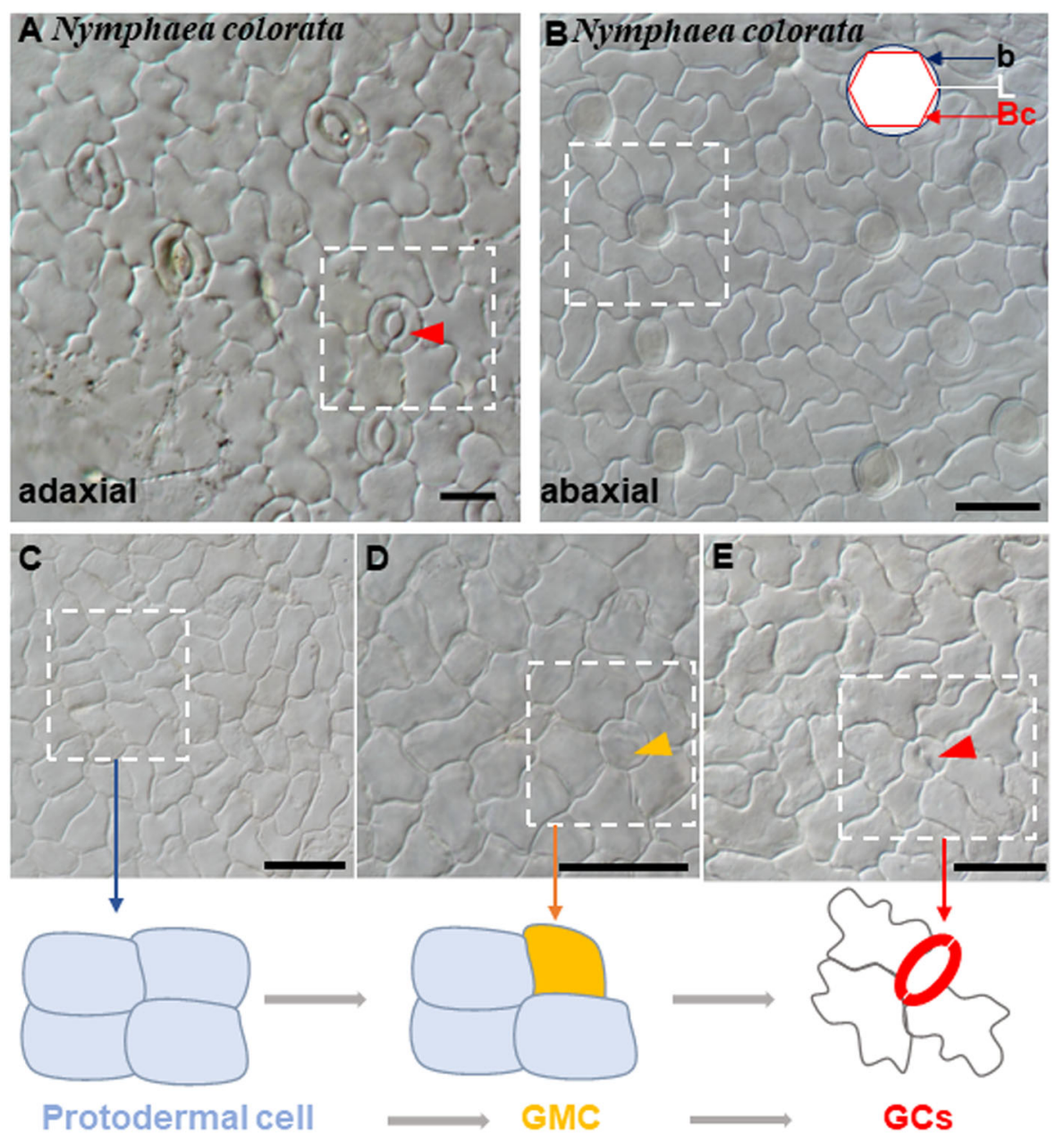

Fig. 1 Stomatal structures and development process in Nymphaea colorata. a The upper epidermis of N. colorata with anomocytic stomata. b Abaxial hydropote complex structures of N. colorata with base (b) formed by anticlinal contact cell walls, the lens-shaped cell (L), and the bowlshaped cell (Bc). c-e Micrograph of stomata at different developmental stages in adaxial leaf surfaces. c Squared patterning, a protodermal cell. d Large round cells are putative GMCs (orange arrow). e Stage with maturing stomata (red arrow). Schematic diagram of stomatal development. A protodermal cell (pale blue) that differentiated directly into a guard mother cell (orange); then, the GMC divided into GCs (red) 
searches to selectively look for similar protein sequences from these genomes ${ }^{26}$. A MAFFT (Multiple Sequence Alignment program) was chosen to produce an alignment of all amino-acid sequences with a BLAST score of at least 60 against $A$. thalian ${ }^{27}$. The phylogenetic tree was reconstructed using the maximum likelihood (ML) method in FastTree2 ${ }^{28}$.

Protein domains were identified using the National Center for Biotechnology Information conserved domain search tool. PEST domains were identified using emboss. bioinformatics.nl/cgi-bin/emboss/epestfind.

\section{Results}

Loss of stomatal development genes in $N$. colorata

It was reported that different stomatal development patterns occur in plants of the ANITA grade. A. trichopoda possesses mostly perigenous and mesoperigenous stomata ${ }^{9}$. In this species, protodermal cells can directly become GMCs or divide asymmetrically to produce
GMCs and stomatal lineage ground cells ${ }^{9}$. However, in Nymphaea, protodermal cells seemed to skip asymmetric divisions and directly gave rise to $\mathrm{GMCs}^{7,9}$. It is still to be determined whether asymmetric division is an ancestral stomata-forming step during evolution.

To gain a deeper understanding of the ancestral development of stomatal structure, we performed anatomic observation of the stomatal structure in $N$. colorata. We found that $N$. colorata stomata are only present on the adaxial surface of the floating leaf, with each stoma surrounded by 4-8 neighbouring cells (Fig. 1a). On the abaxial surface of $N$. colorata, we only found hydropote complexes with lens-shaped cells and bowl-shaped cells, which appeared to be surrounded by specialized rosettes of epidermal cells (Fig. 1b). It was hypothesized that the hydropote in Nymphaea colorata is homologous to stomatal complexes, and its functions and morphologies are highly associated with aquatic habitats ${ }^{29}$. Similarly, another floating plant, S. polyrhiza, has lost stomata on

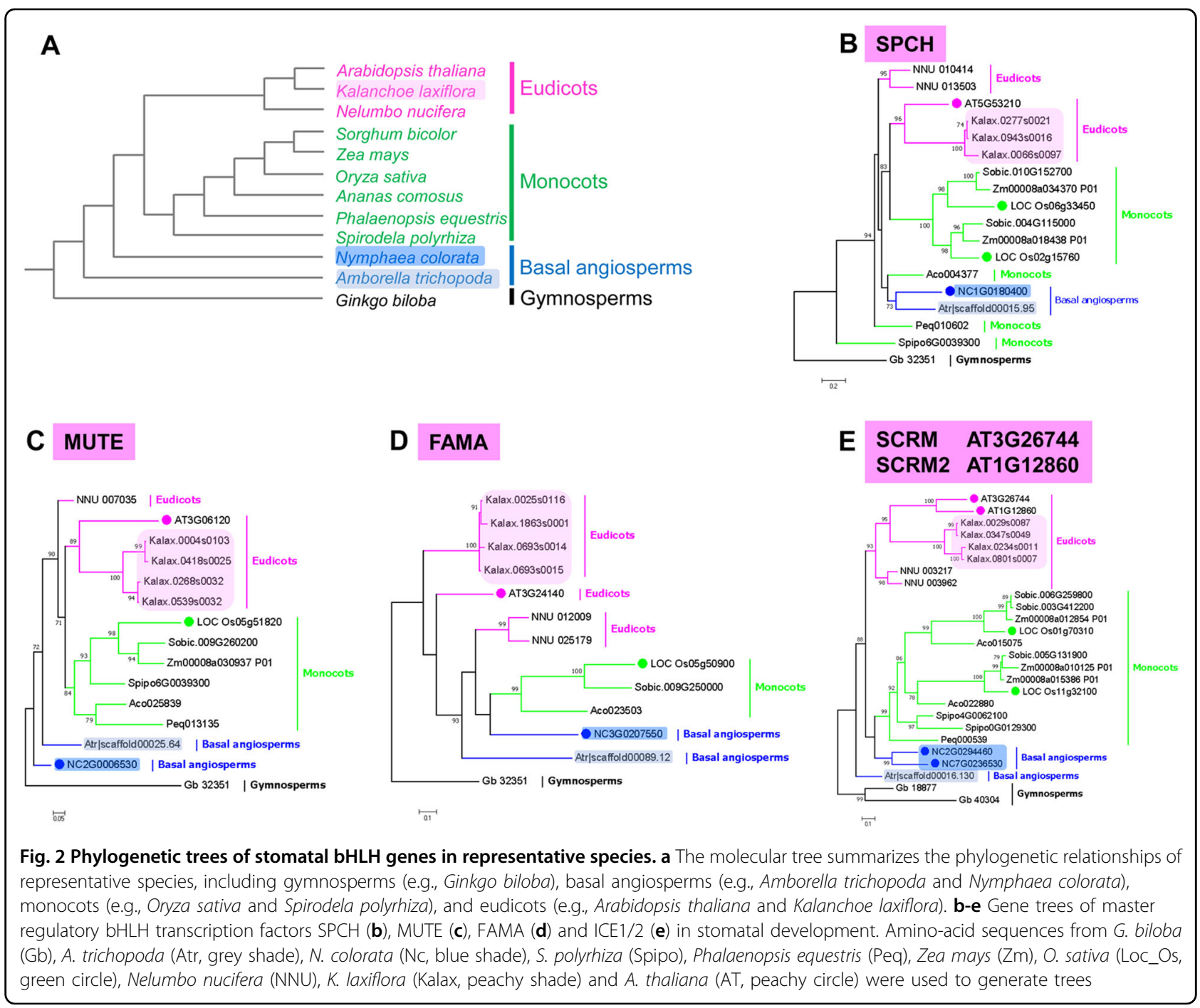



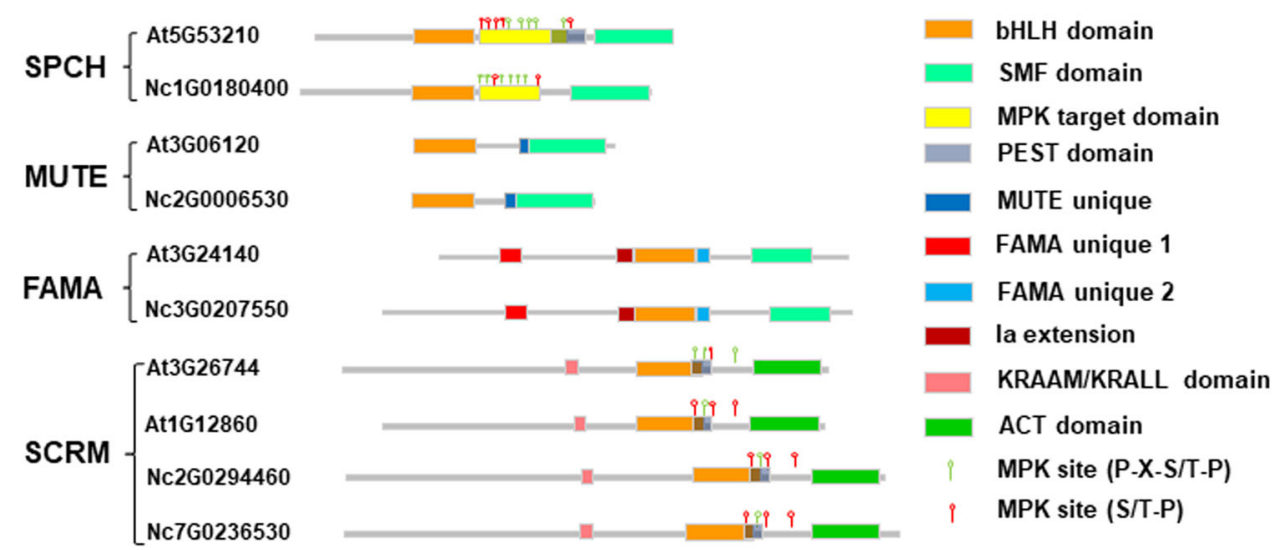

Fig. 3 Schematics of the domain architecture of SPCH, MUTE, FAMA, and ICE-like sequences from N. colorata (Nc) and A. thaliana (At). NcSPCH shares the bHLH domain (orange) and C-terminal SMF domain (light blue) with AtSPCH but has no protein degradation-associated PEST domain (grey) and has a shorter MAPK target domain (yellow). Both NCMUTE and AtMUTE genes have a unique conserved region (MUTE unique, dark blue) and lack some residues preceding the bHLH domain that are present in all the other bHLH la members with various lengths. Both NcFAMA and AtFAMA genes have high AA sequence similarity and harbour three unique domains (FAMA unique 1, red; FAMA unique 2, blue; la extension, brown). Both NCICE-like and AtICE1/2 have highly conserved bHLH domains, potential PEST domains and ACT domains (green)

\section{A EPF2}

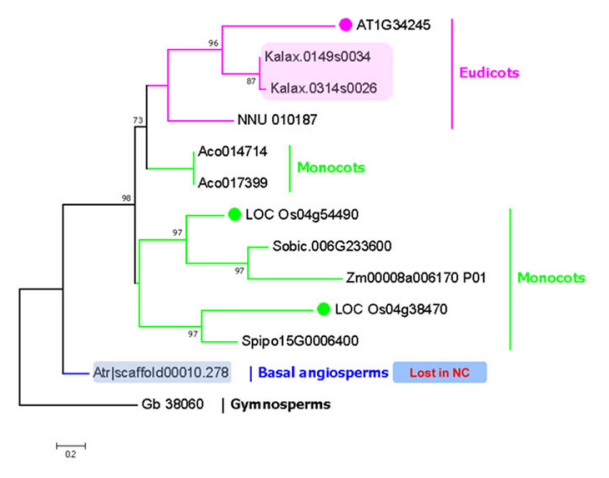

\section{BASL}

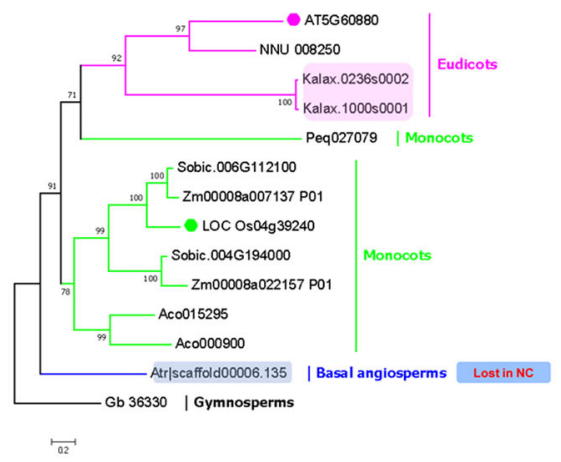

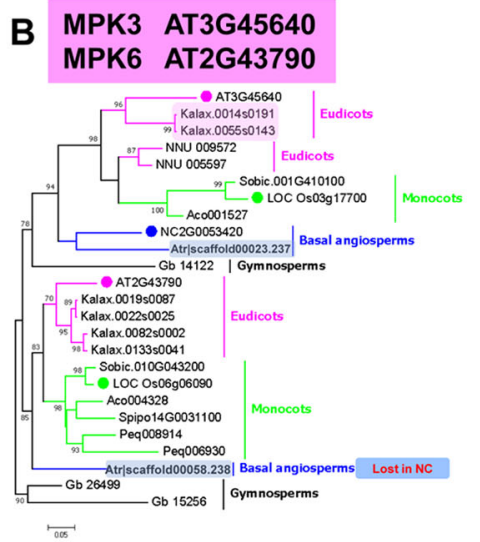

\section{C $\mathrm{AP2C3}$}

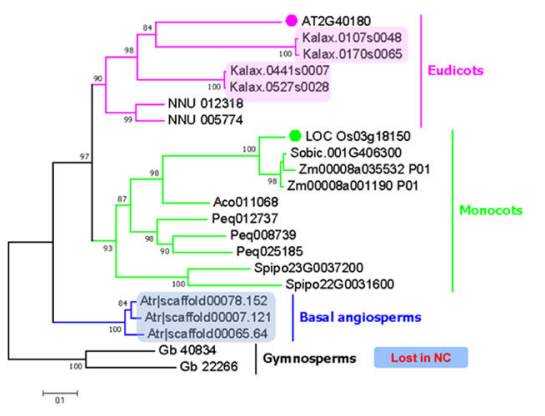

Doss

\section{E POLAR}

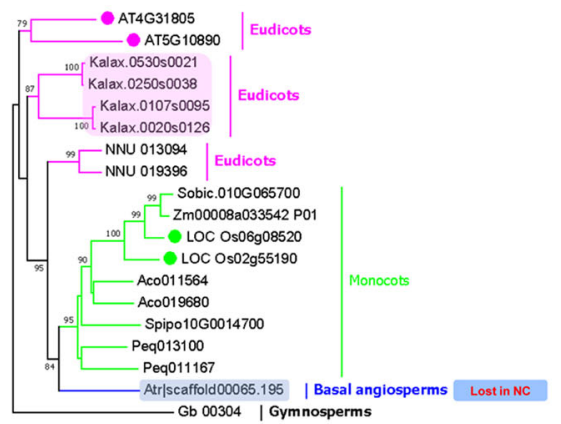

$\stackrel{\cdot a}{0.1}$

Fig. 4 Phylogenetic analysis of genes lost in $\mathbf{N}$. colorata. Phylogenetic trees constructed using amino-acid sequences of selected A. thaliana EPF2 (a), MPK3/MPK6 (b), AP2C3 (c), BASL (d) and POLAR (e) gene family members. Amino-acid sequences from G. biloba (Gb), A. trichopoda (Atr, grey shade), N. colorata (Nc, blue shade), S. polyrhiza (Spipo), P. equestris (Peq), Z. mays (Zm), O. sativa (Os, green circle), N. nucifera (NNU), K. laxiflora (Kalax, peachy shade) and $A$. thaliana (AT, peachy circle) were used to generate trees 
the abaxial surface (Figure S1). These results reveal that floating plants tend to lose stomata or create special stomata-like structures to adapt to the aquatic environment. It can also be exemplified by seagrass, Zostera marina, in which no stomata are present on leaves, and coincidently, entire stomatal genes are lost to adapt to the marine lifestyle ${ }^{30}$. Although anatomical descriptions of stomatal development have been reported for many taxa, little is known about the evolution of the molecular machine of stomatal formation across land plants.

One way to understand the evolution of these essential regulators of stomatal development is to analyse their phylogenies. This is currently feasible based on the genome sequences for many species, including the eudicots A. thaliana and K. laxiflora; the monocot plants O. sativa and $Z$. mays. To facilitate our understanding of the early evolution of these regulators, we included basal angiosperms $A$. trichopoda, and we recently sequenced the genome of an early-divergent angiosperm $N$. colorata (see Materials and methods for information on genome data) (Fig. 2a). To understand some special features of stomata formation in $N$. colorata, we analysed the potential orthologues of $A$. thaliana genes involved in stomatal formation using the unique unpublished genome data of water lily. In line with $A$. thaliana, we found high conservation of the core genes required for stomatal formation in $N$. colorata, including an orthologue of an $\mathrm{SPCH}$-like gene, $\mathrm{NcSPCH}$ (Fig. 2b); orthologue of a MUTE-like gene, NcMUTE (Fig. 2c); orthologue of a FAMA-like gene, NcFAMA (Fig. 2d), and two orthologues of an ICE/SCRM-like gene, NcICE1 and NcSCRM2 (Fig. 2e). We further analysed the conservation of the homologous domain of these proteins and found a high degree of domain conservation (Fig. 3). However, we also found a number of genes missing from the $N$. colorata genome, including the peptide ligands EPF2, MPK6, and AP2C3 and the polarity controllers BASL and POLAR (Fig. 4). Interestingly, the function of lost genes seems to be highly specific to the asymmetric stomatal development stages.

\section{Stomatal development gene duplications in K. laxiflora}

Whole-genome duplications (WGDs) are a common phenomenon during evolution, and the resulting gene duplications (GDs) provide redundant functions or specified novel functions ${ }^{31-34}$. WGDs are the source of functional diversity or novelty in the genome for adaption to environmental changes ${ }^{35}$. It has been suggested that two distinct WGDs occur in the K. laxiflora lineage and generate four gene copies across the genome ${ }^{36}$.

To understand the evolution of CAM stomata-related genes, we performed genome phylogenetic analysis in $K$.

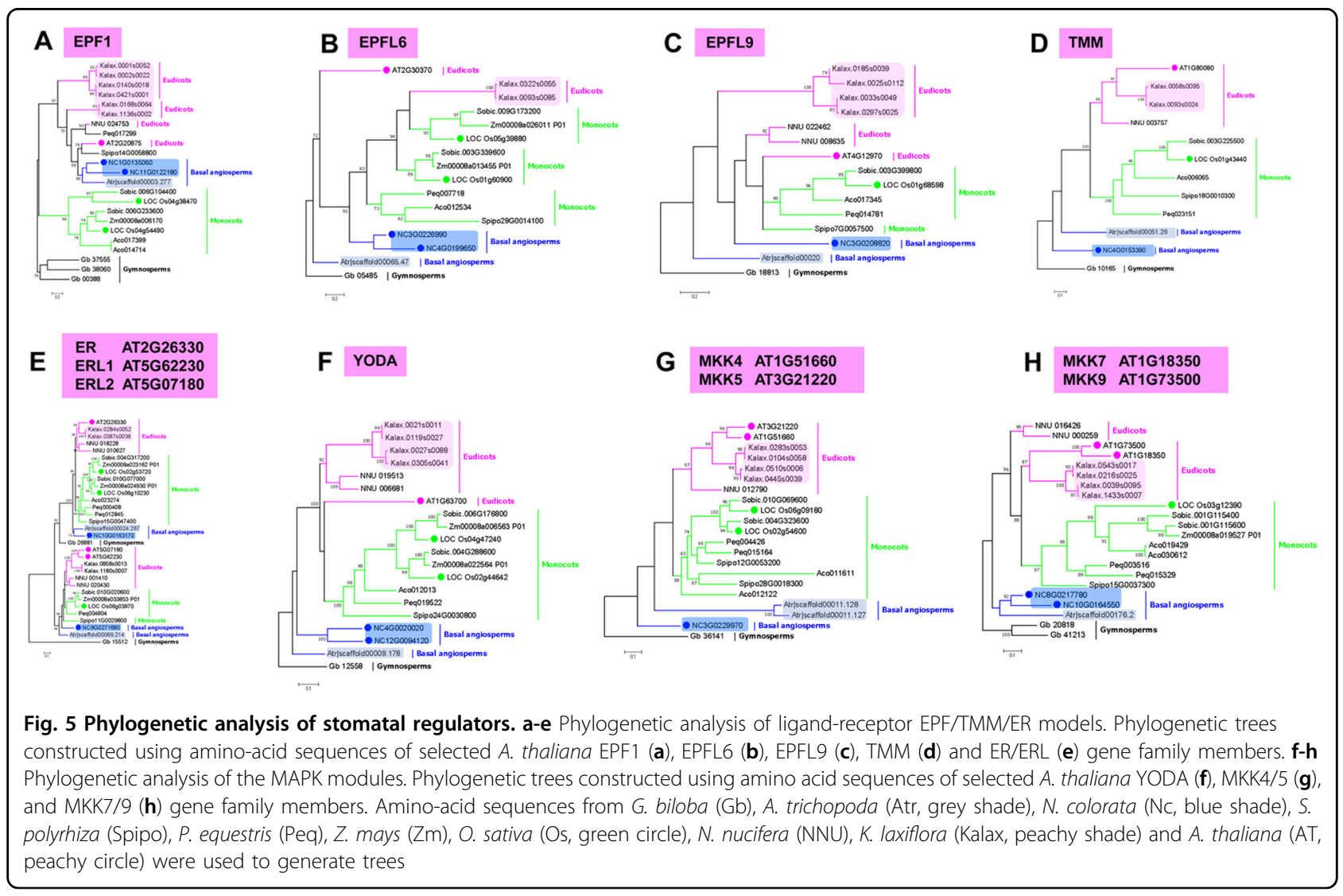




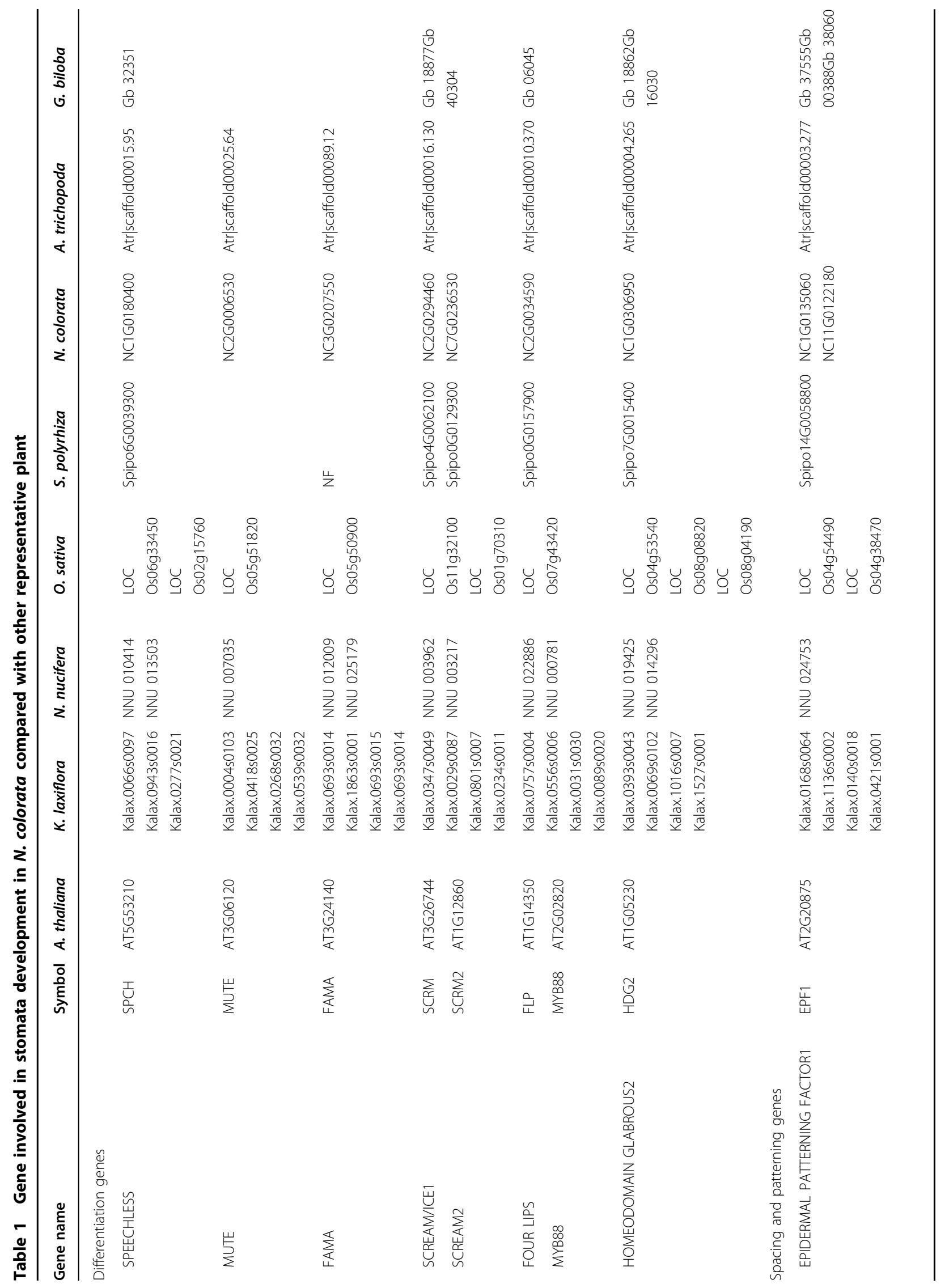




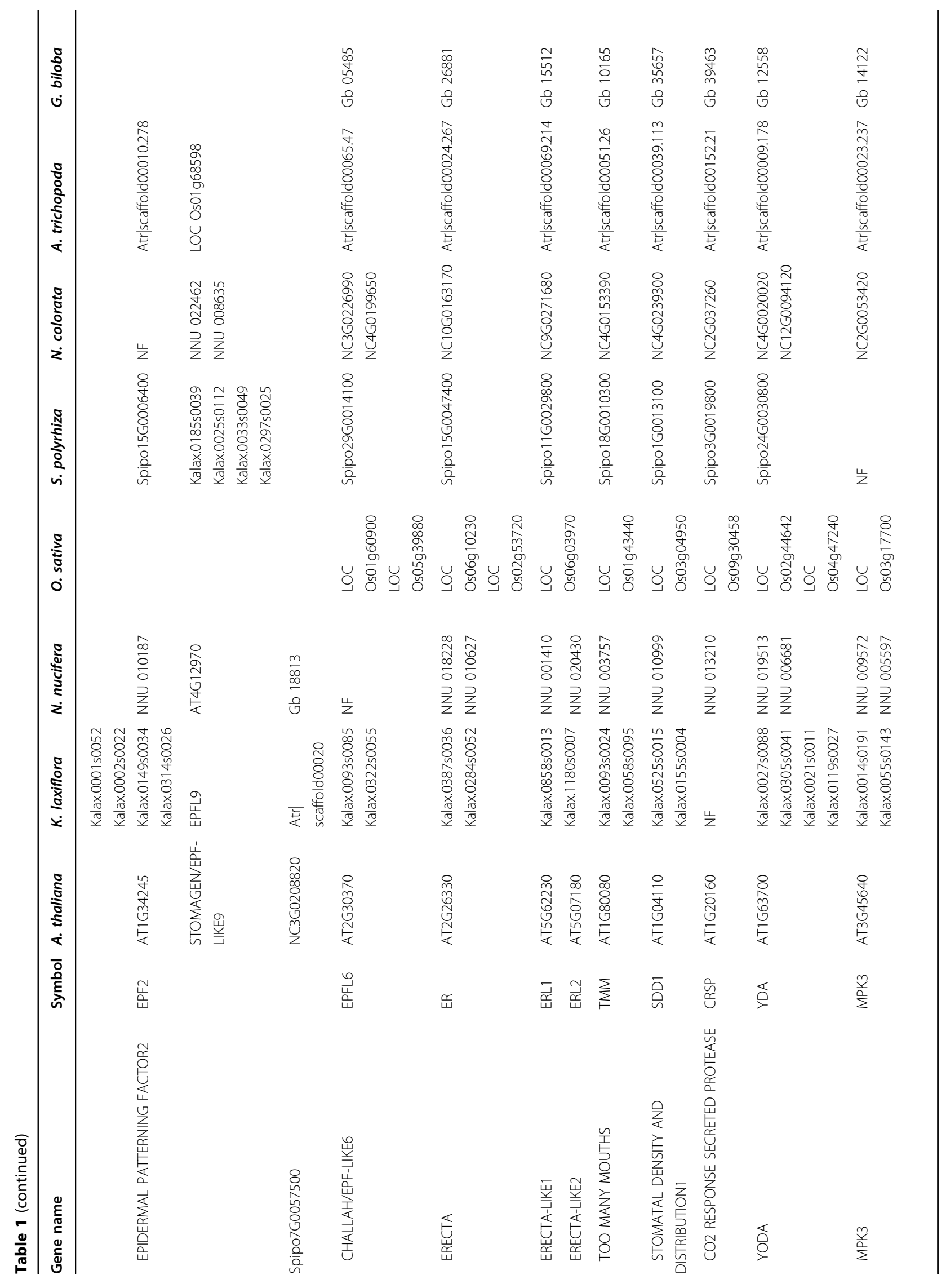




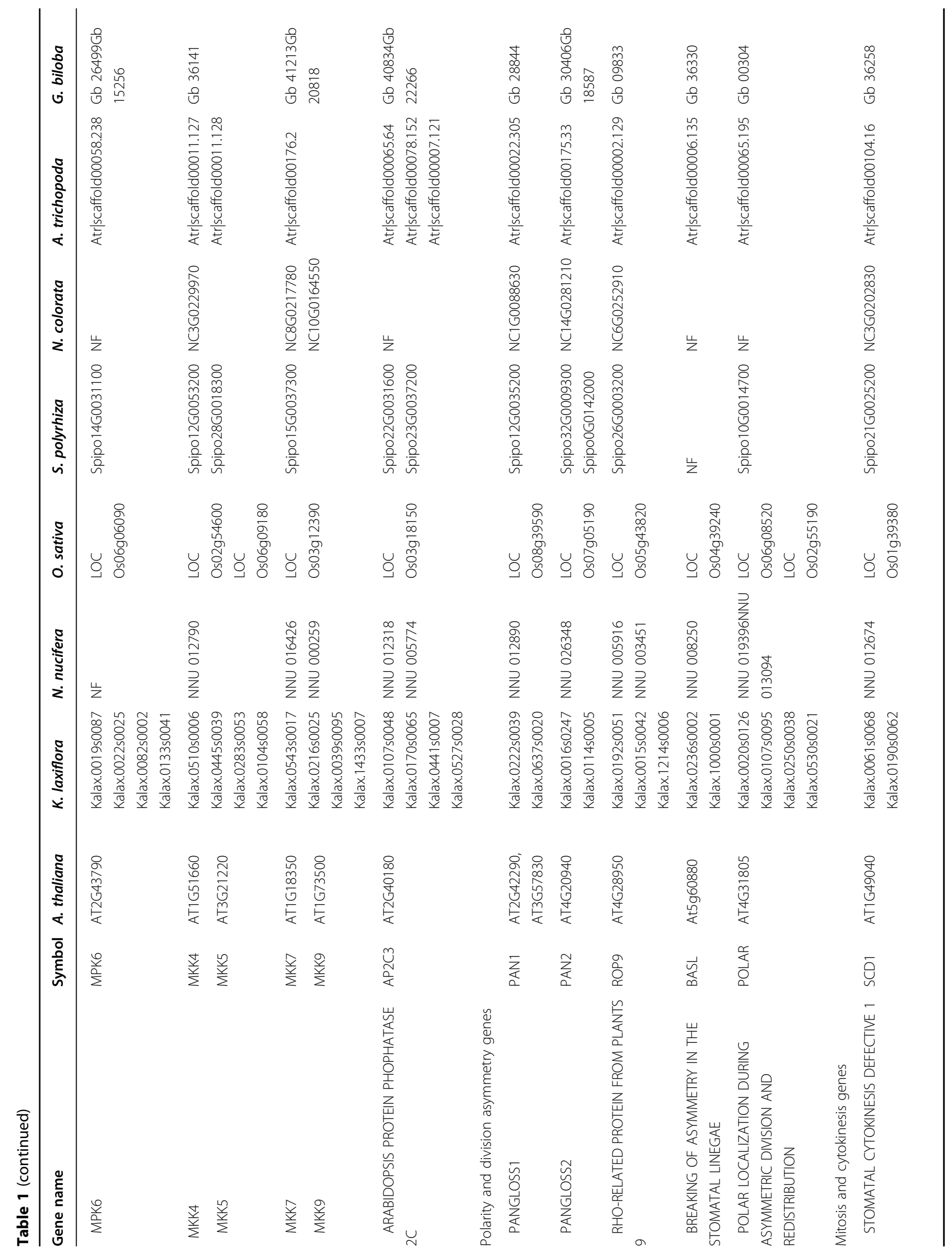




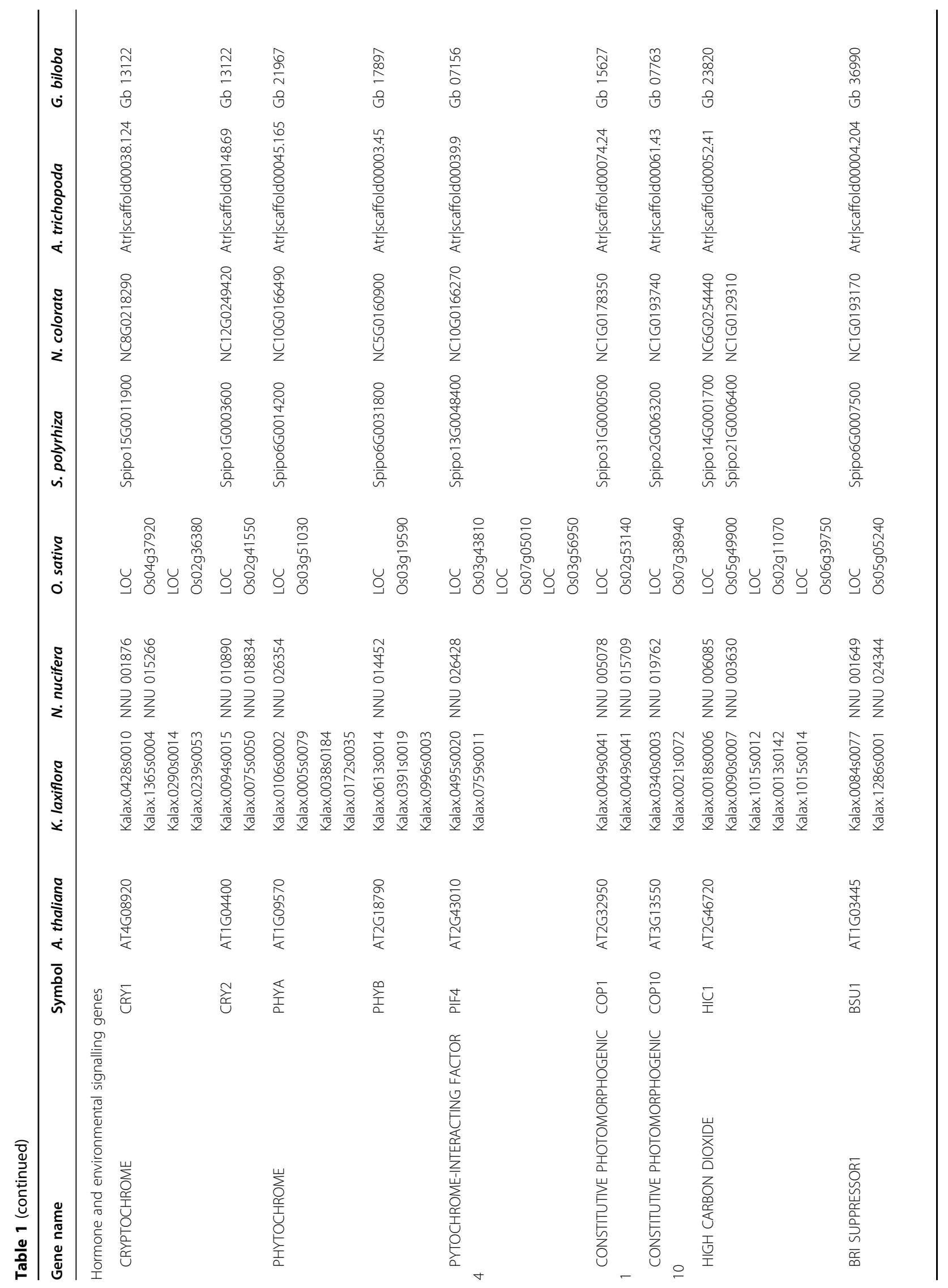




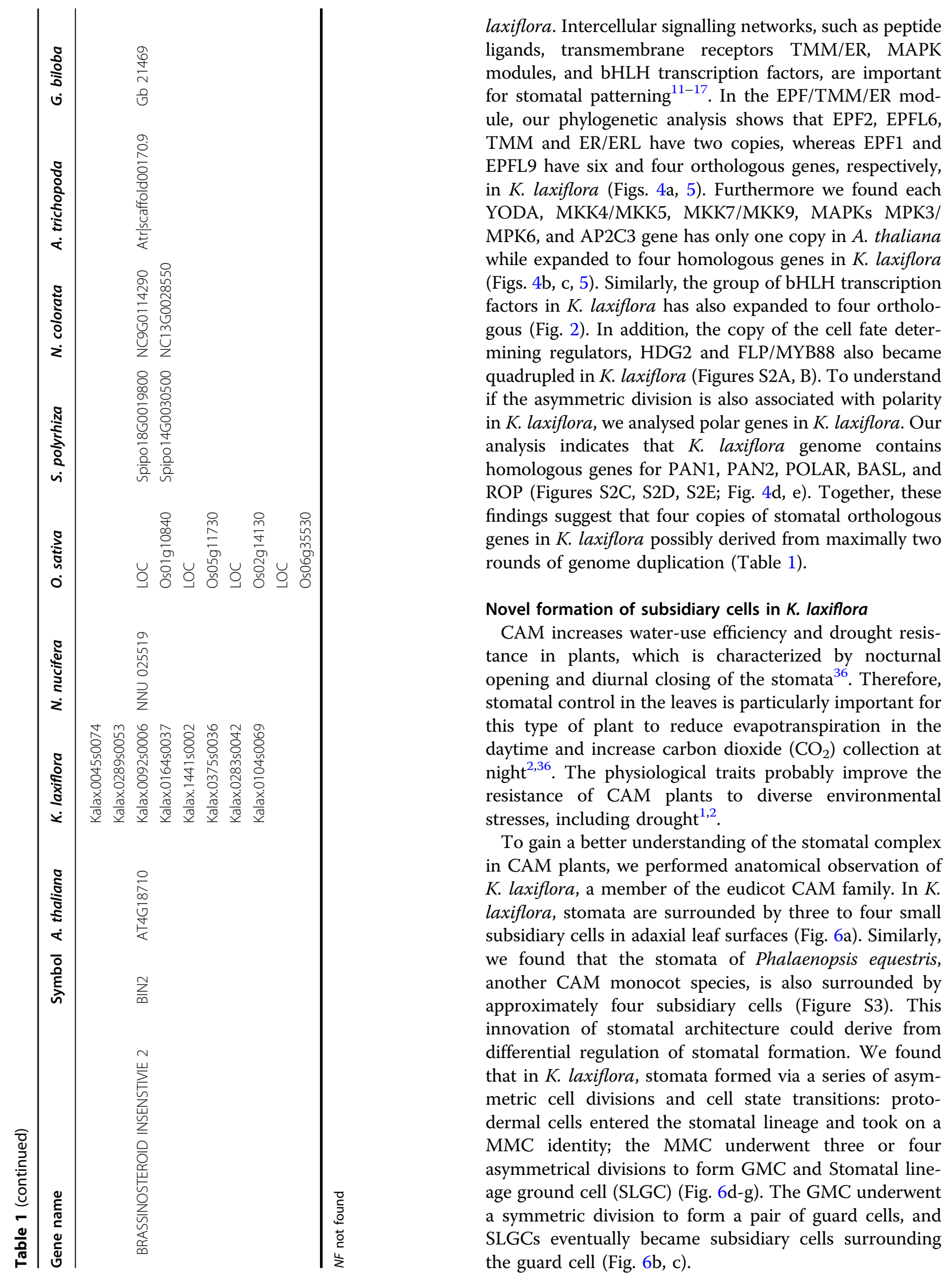

laxiflora. Intercellular signalling networks, such as peptide ligands, transmembrane receptors TMM/ER, MAPK modules, and bHLH transcription factors, are important for stomatal patterning ${ }^{1-17}$. In the EPF/TMM/ER module, our phylogenetic analysis shows that EPF2, EPFL6, TMM and ER/ERL have two copies, whereas EPF1 and ectively, while expanded to four homologous genes in K. laxiflora (Figs. 4b, c, 5). Similarly, the group of bHLH transcription factors in K. laxiflora has also expanded to four orthologous (Fig. 2). In addition, the copy of the cell fate determining regulators, HDG2 and FLP/MYB88 also became quadrupled in K. laxiflora (Figures S2A, B). To understand if the asymmetric division is also associated with polarity in K. laxiflora, we analysed polar genes in K. laxiflora. Our analysis indicates that $K$. laxiflora genome contains homologous genes for PAN1, PAN2, POLAR, BASL, and ROP (Figures S2C, S2D, S2E; Fig. 4d, e). Together, these findings suggest that four copies of stomatal orthologous maximally two

\section{ovel formation of subsidiary cells in $K$. laxiflora}

CAM increases water-use efficiency and drought resisopening and diurnal closing of the stomata ${ }^{36}$. Therefore, stomatal control in the leaves is particularly important for this type of plant to reduce evapotranspiration in the daytime and increase carbon dioxide $\left(\mathrm{CO}_{2}\right)$ collection at night $^{2,36}$. The physiological traits probably improve the resistance of CAM plants to diverse environmental resses, including drought ${ }^{1,2}$

To gain a better understanding of the stomatal complex in CAM plants, we performed anatomical observation of laxiflora, stomata are surrounded by three to four small subsidiary cells in adaxial leaf surfaces (Fig. 6a). Similarly, we found that the stomata of Phalaenopsis equestris, another CAM monocot species, is also surrounded by innovation of stomatal architecture could derive from differential regulation of stomatal formation. We found that in K. laxiflora, stomata formed via a series of asymmetric cell divisions and cell state transitions: protodermal cells entered the stomatal lineage and took on a MMC identity; the MMC underwent three or four asymmetrical divisions to form GMC and Stomatal lineage ground cell (SLGC) (Fig. 6d-g). The GMC underwent SLGCs eventually became subsidiary cells surrounding the guard cell (Fig. 6b, c). 

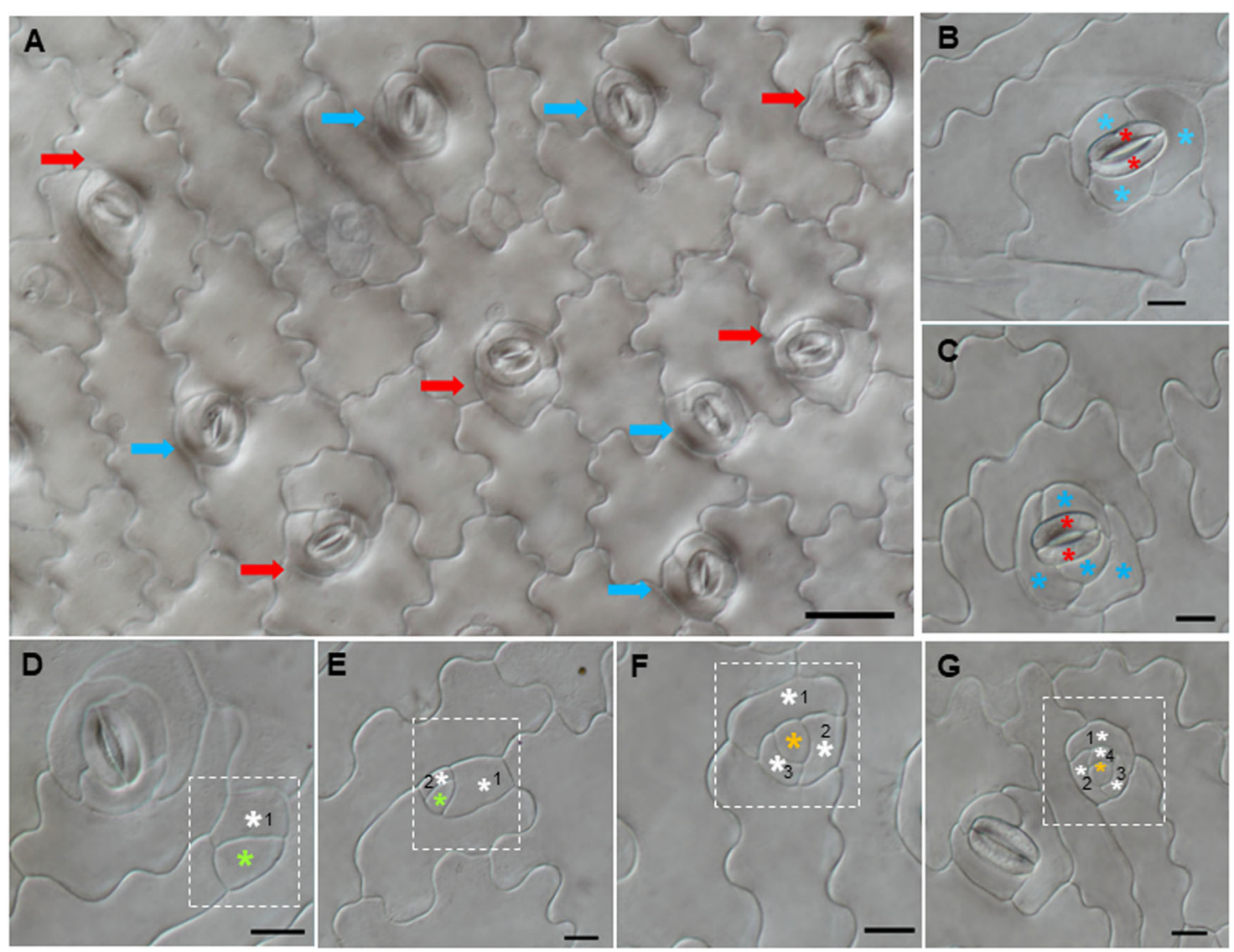

Fig. 6 Stomatal development of Kalanchoe laxiflora on adaxial leaf epidermis. a There are two types of mature stomata equably distributed on adaxial leaf surfaces; the guard cells are surrounded by three (blue arrow) or four subsidiary cells (red arrow). b A stoma with three subsidiary cells. c A stoma with four subsidiary cells. $\mathbf{d}-\mathbf{g}$ DIC of different stages with asymmetric division finally form two mature stomatal types. Meristemoid (green star), surrounding cells (white star), guard mother cell (orange star), guard cells (red star), and subsidiary cells (blue star)

It is widely accepted that different stomatal patternings reflect the asymmetric division of precursor cells and lateral divisions of neighbouring cells ${ }^{37}$. For example, in anomocytic stomata occurring in the eudicot $A$. thaliana (Fig. 7a, b), the MMC underwent three asymmetric divisions to give rise to a GMC and SLGCs, which was followed by a transition from SLGCs to pavement cells (Fig. 7c). Although both A. thaliana and K. laxiflora are eudicots, $K$. laxiflora possesses stephanocytic stomata (Fig. 7d, e). Developmentally, there is a similarity between these two types of stomata: meristemoids undergo a series of asymmetric divisions to produce SLGCs surrounding guard cells (Fig. 7f), and different cell fate choices of SLGCs finally give rise to different stomatal complexes (Figure S4). In monocot species such as $O$. sativa, the type of mature stomata is named the paracytic type, in which the guard cell is surrounded by two subsidiary cells (Fig. $7 \mathrm{~g}, \mathrm{~h}$ ). In this type, the stomatal meristemoid divides asymmetrically to form a larger SLGC and a smaller meristemoid that directly forms the GMC. Before the GMC divides, it induces neighbouring cell files to adopt an SMC identity, which subsequently forms SCs via asymmetric divisions. The GMC then undergoes symmetric mitosis to eventually form guard cells (Fig. 7i). Therefore, subsidiary cells can develop through different ways: one is through asymmetric division in O. sativa, and the other is through SLGC differentiation in K. laxiflora. In $K$. laxiflora, subsidiary cells are noticeably visible, but little is known about the factors defining subsidiary cell identity. In Brachypodium distachyon, subsidiary cells are formed through asymmetric divisions. BdMUTE is an orthologue of $A$. thaliana MUTE that has been identified as sufficient for SC formation based on its acquisition of cell-to-cell mobility ${ }^{23}$. In A. thaliana, AtMUTE, which is associated with GMC identity, is nonmobile. The question is whether the KalaxMUTE could also specify SC identity by being mobile. To address this, we compared MUTE orthologues of the representative species with $B$. distachyon, $A$. thaliana and $K$. laxiflora to test potential mobility motifs in K. laxiflora (Fig. 8). Our results show high conservation in the bHLH functional domain. The differences in potential mobility residues of KalaxMUTE 


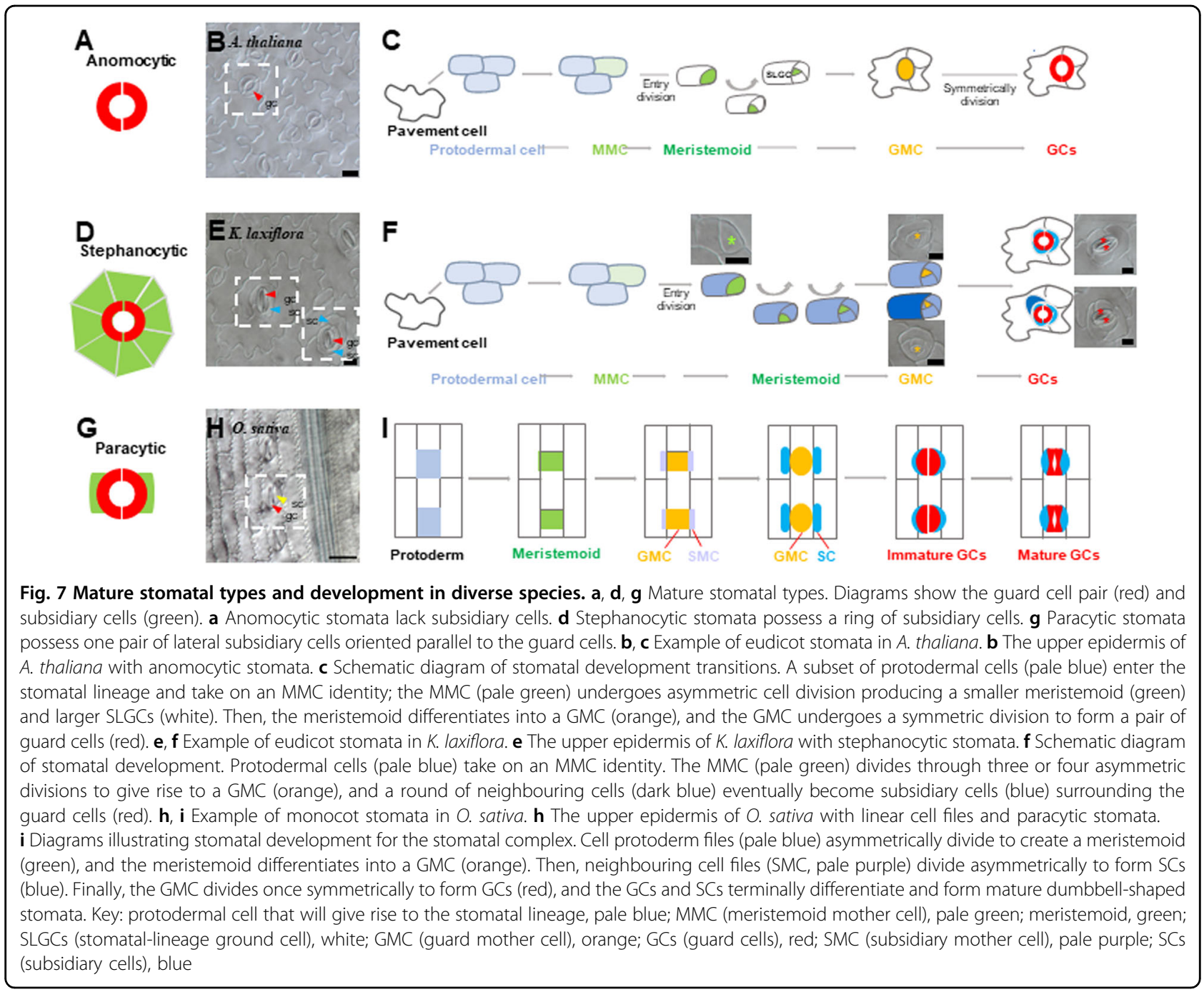

from its homologue in $B$. distachyon are similar to those in A. thaliana. Thus, the subsidiary cells in K. laxiflora may not be specified by KalaxMUTE mobility.

\section{Discussion}

Stomatal patterning is diverse among different land plants. In Physcomitrella patens, stomata exhibit partial or complete division to form a single GC or paired GCs, respectively ${ }^{38}$. Moss does not have genes encoding MUTE or $\mathrm{SPCH}$ and uses genes encoding two bHLH proteins, PpSMF1 and PpSCRM1, to promote stomatal formation $^{39}$. In $A$. thaliana, the stomata are surrounded by two kidney-shaped guard cells, and polar localization of BASL is required for a series of asymmetric divisions to form the stomatal structure ${ }^{40}$. In O. sativa, polar localization of PAN protein is responsible for subsidiary cell asymmetry in the stomatal complex ${ }^{10}$. In B. distachyon, BdMUTE is necessary and sufficient for SC formation. However, AtMUTE in $A$. thaliana defines GC precursor fate ${ }^{23}$.
Overall, it appears that the function of most genes is conserved during stomatal formation across plant evolution, but there are novel genes recruited to regulate unique aspects of stomatal patterning in some species.

The regulatory machine of stomata development appeared to be flexible and adaptable during evolution. The adaptation pressure could quickly change the division and differentiation pattern during stomata formation. For example, all the genes involved in stomatal differentiation are lost in seagrass Zostera to enhance its adaptation to marine lifestyle ${ }^{30}$. Plants of the ANITA grade form specialized structures in the epidermal cells to adapt to its habitat ${ }^{29}$. Similarly, $N$. colorata has lost genes, which could be associated with its unique stomatal development. However, further molecular and genetic manipulations are needed for functional verification.

Compared with our understanding of stomatal development in model systems, little is known about the molecular evolution of stomatal morphology, particularly 


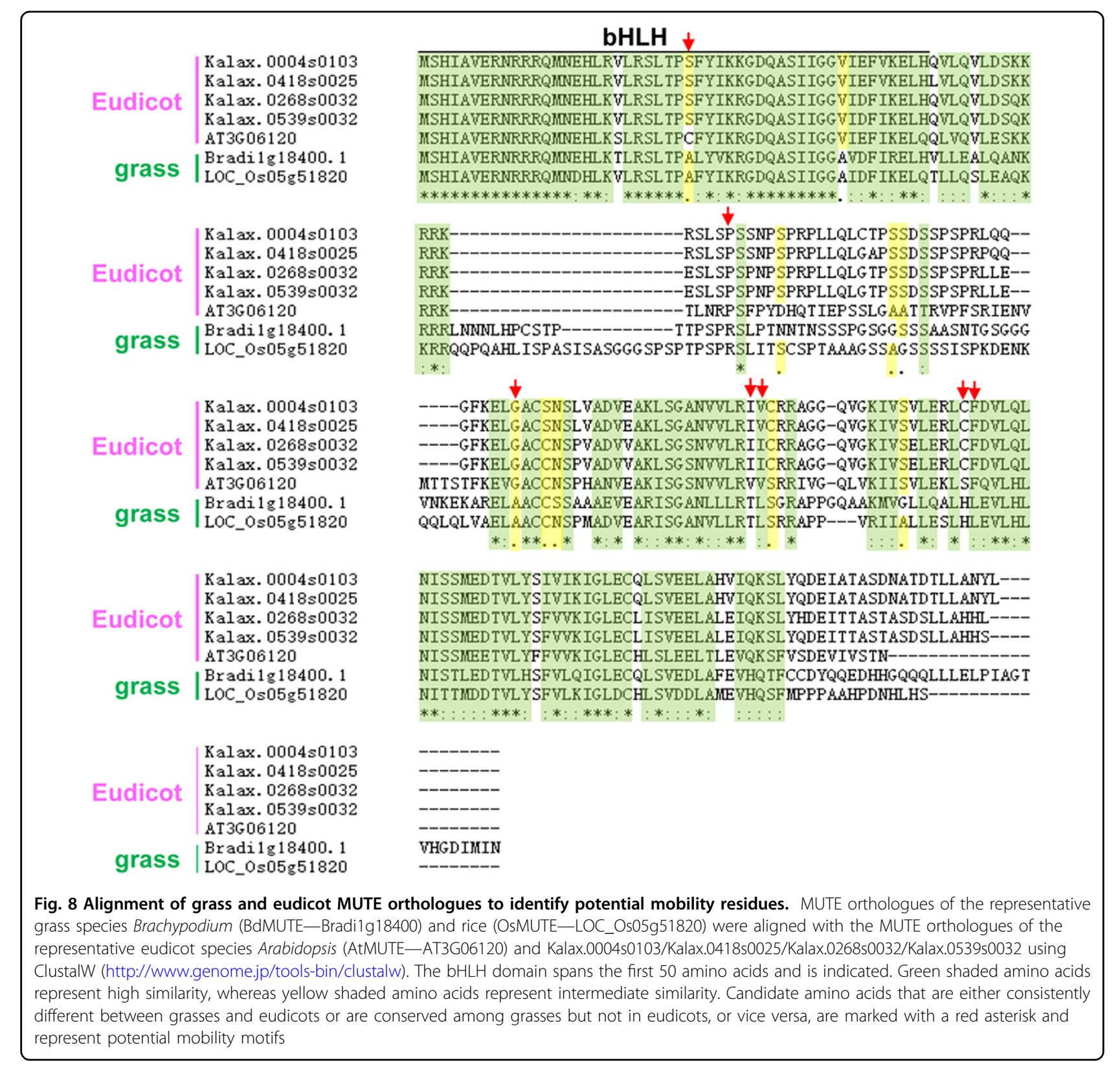

in basal angiosperms. Alongside the completion of the genome, we are beginning to find the comparative molecular basis of the evolution of stomatal development and identify orthologues of stomatal regulator genes in a selected range of phylogenetic taxa. However, it is still technically difficult to analyse the function of orthologues. In the $N$. colorata genome, we found that a number of the genes that are highly specific to the stomatal asymmetric division were missing. Taken together, these results suggest that most core regulators of stomata formation remain conserved during evolution, whereas some gene loss events can occur to modify stomata formation processes, such as asymmetric division. These changes at the genetic and morphological levels of individual species may result from adaptation to inhabitant environments rather than evolutionary changes.

Recent studies have indicated that WGD events are ubiquitous in the evolution of angiosperms, and WGDs tend to retain multiple family duplications to increase the frequency of multiplication and the function of genes ${ }^{41}$. Thus, WGDs are widely thought to provide genomic novelties and complexities to promote plant adaptation to environments $^{42}$. Large-scale GDs involved in stomata development through WGDs in K. laxiflora have been identified ${ }^{36}$.

Analysis of the genes involved in stomata formation showed that the protein sequences of the core genes 
required to instigate and pattern stomata are conserved in $K$. laxiflora (Table 1). It is unclear whether the expression or protein modification of these regulators is different in $K$. laxiflora compared with that in A. thaliana. Indeed, the duplication of stomata regulator genes appears to be a common theme in K. laxiflora, but the extent to which this represents a divergence in gene function requires further studies.

It seemed that genes encoding critical developmental regulators were more likely to be retained during evolution $^{43,44}$. For stomatal development, subsidiary cells can occur from an adjacent cell file or the same cell as the guard cells. Based on sequence conservation, the mobility of KalaxMUTE could be similar to its homologue in Arabidopsis. Thus, it is less likely that the modification of KalaxMUTE leads to featured stomatal subsidiary cells in $K$. laxiflora. Further work is needed to investigate whether the gene gains in $K$. laxiflora are associated with subsidiary cell establishment.

\section{Acknowledgements}

This study was supported by the 1000-Talents Plan from China for young researchers (grant KXR15012A), the National Key Research and Development Program of China (2016YFD0100700) and a grant from the National Natural Science Foundation of China (31722006) to S.W.

\section{Author contributions}

S.W. and L.Z. designed the research; M.X. and S.Q. performed the experiments; M.X., S.Q., F.C., and S.W. analysed the data; M.Z. and S.W. wrote the paper.

\section{Conflict of interest}

The authors declare that they have no conflict of interest.

Supplementary Information accompanies this paper at https://doi.org/ 10.1038/s41438-018-0048-8.

Received: 14 January 2018 Revised: 22 April 2018 Accepted: 26 April 2018 Published online: 01 August 2018

\section{References}

1. Luttge, U. Ability of crassulacean acid metabolism plants to overcome interacting stresses in tropical environments. AoB Plants 2010, plq005 (2010).

2. Borland, A. M. et al. Engineering crassulacean acid metabolism to improve water-use efficiency. Trends Plant. Sci. 19, 327-338 (2014).

3. Vatén, A. \& Bergmann, D. C. Mechanisms of stomatal development: an evolutionary view. EvoDevo 3, 11 (2012).

4. Peterson, K. M., Rychel, A. L. \& Torii, K. U. Out of the mouths of plants: the molecular basis of the evolution and diversity of stomatal development. Plant Cell 22, 296-306 (2010).

5. Males, J. \& Griffiths, H. Stomatal biology of CAM plants. Plant Physiol. 174, 550-560 (2017)

6. Chen, Z. et al. Molecular evolution of grass stomata. Trends Plant. Sci. 22, 124-139 (2017)

7. Carpenter, K. J. Stomatal architecture and evolution in basal angiosperms. Am. J. Bot. 92, 1595-1615 (2005).

8. Gallagher, K. \& Smith, L. G. Roles for polarity and nuclear determinants in specifying daughter cell fates after an asymmetric cell division in the maize leaf. Curr. Biol. 10, 1229-1232 (2000).

9. Rudall, P. J. \& Knowles, E. V. W. Ultrastructure of stomatal development in earlydivergent angiosperms reveals contrasting patterning and pre-patterning. Ann. Bot. 112, 1031-1043 (2013).
10. Pillitteri, L. J. \& Torii, K. U. Mechanisms of stomatal development. Annu. Rev. Plant. Biol. 63, 591-614 (2012).

11. Hara, K., Kajita, R., Torii, K. U., Bergmann, D. C. \& Kakimoto, T. The secretory peptide gene EPF1 enforces the stomatal one-cell-spacing rule. Genes Dev. $\mathbf{2 1}$ 1720-1725 (2007).

12. Hunt, L. \& Gray, J. E. The signaling peptide EPF2 controls asymmetric cell divisions during stomatal development. Curr. Biol. 19, 864-869 (2009).

13. Wang, H., Ngwenyama, N., Liu, Y., Walker, J. C. \& Zhang, S. Stomatal development and patterning are regulated by environmentally responsive mitogen-activated protein kinases in Arabidopsis. Plant Cell 19, 63-73 (2007)

14. Pillitteri, L. J., Sloan, D. B., Bogenschutz, N. L. \& Torii, K. U. Termination of asymmetric cell division and differentiation of stomata. Nature 445, 501-505 (2007).

15. Pillitteri, L. J., Bogenschutz, N. L. \& Torii, K. U. The bHLH protein, MUTE, controls differentiation of stomata and the hydathode pore in Arabidopsis. Plant Cell Physiol. 49, 934-943 (2008).

16. Ohashi-lto, K. \& Bergmann, D. C. Arabidopsis FAMA controls the final proliferation/ differentiation switch during stomatal development. Plant Cell 18, 2493-2505 (2006).

17. Kanaoka, M. M. et al. SCREAM/ICE1 and SCREAM2 specify three cell-state transitional steps leading to Arabidopsis stomatal differentiation. Plant Cell $\mathbf{2 0}$ 1775-1785 (2008)

18. Dong, J., MacAlister, C. A. \& Bergmann, D. C. BASL controls asymmetric cell division in Arabidopsis. Cell 137, 1320-1330 (2009).

19. Pillitteri, L. J. Peterson, K. M. Horst, R. J. \& Torii, K. U. Molecular profiling of stomatal meristemoids reveals new component of asymmetric cell division and commonalities among stem cell populations in Arabidopsis. Plant Cell $\mathbf{2 3}$ 3260-3275 (2011)

20. Cartwright, H. N., Humphries, J. A. \& Smith, L. G. PAN1: a receptor-like protein that promotes polarization of an asymmetric cell division in maize. Science 323, 649-651 (2009).

21. Zhang, X. et al. Identification of PAN2 by quantitative proteomics as a leucinerich repeat-receptor-like kinase acting upstream of PAN1 to polarize cell division in maize. Plant Cell 24, 4577-4589 (2012).

22. Humphries, J. A. et al. ROP GTPases act with the receptor-like protein PAN1 to polarize asymmetric cell division in maize. Plant Cell 23, 2273-2284 (2012)

23. Raissig, M. T. et al. Mobile MUTE specifies subsidiary cells to build physiologically improved grass stomata. Science 355, 1215-1218 (2017).

24. Cai, S., Papanatsiou, M., Blatt, M. R. \& Chen, Z. H. Speedy grass stomata: emerging molecular and evolutionary features. Mol. Plant 10 912-914 (2017).

25. Raissig, M. T., Abrash, E., Bettadapur, A., Vogel, J. P. \& Bergmann, D. C. Grasses use an alternatively wired bHLH transcription factor network to establish stomatal identity. Proc. Natl. Acad. Sci. USA. 113, 8326-8331 (2016).

26. Altschul, S. F., Gish, W., Miller, W., Myers, E. W. \& Lipman, D. J. Basic local alignment search tool. J. Mol. Biol. 215, 403-410 (1990).

27. Katoh, K. \& Standley, D. M. MAFFT multiple sequence alignment software version 7: improvements in performance and usability. Mol. Biol. Evol. 30 772-780 (2013).

28. Price, M. N., Dehal, P. S. \& Arkin, A. P. FastTree: computing large minimum evolution trees with profiles instead of a distance matrix. Mol. Biol. Evol. 26 1641-1650 (2009).

29. Carpenter, K. J. Specialized structures in the leaf epidermis of basal angiosperms: morphology, distribution, and homology. Am. J. Bot. 93, 665-681 (2006).

30. Olsen, J. L. et al. The genome of the seagrass Zostera marina reveals angiosperm adaptation to the sea. Nature 530, 331-335 (2016).

31. Pontes, O. et al. Chromosomal locus rearrangements are a rapid response to formation of the allotetraploid Arabidopsis suecica genome. Proc. Natl. Acad. Sci. USA. 101, 18240-18245 (2004).

32. Mitchell-Olds, T. \& Schmitt, J. Genetic mechanisms and evolutionary significance of natural variation in Arabidopsis. Nature 441, 947-952 (2006).

33. Madlung, A. et al. Genomic changes in synthetic Arabidopsis polyploids. Plant J. 41, 221-230 (2005).

34. Long, M., Betrán, E., Thornton, K. \& Wang, W. The origin of new genes: glimpses from the young and old. Nat. Rev. Genet. 4, 865-875 (2003).

35. Jiao, Y. et al. Ancestral polyploidy in seed plants and angiosperms. Nature $\mathbf{4 7 3}$ 97-100 (2011). 
36. Yang, $X$. et al. The Kalanchoë genome provides insights into convergent evolution and building blocks of crassulacean acid metabolism. Nat. Commun. 8, 1899 (2017).

37. Abrash, E. B. \& Bergmann, D. C. Asymmetric cell divisions: a view from plant development. Dev. Cell. 16, 783-796 (2009).

38. Merced, A. \& Renzaglia, K. S. Patterning of stomata in the moss Funaria: a simple way to space guard cells. Ann. Bot. 117, 985-994 (2016).

39. Chater, C. C. et al. Origin and function of stomata in the moss Physcomitrella patens. Nat. Plants 2, 16179 (2016).

40. Shao, W. \& Dong, J. Polarity in plant asymmetric cell division: division orientation and cell fate differentiation. Dev. Biol. 419, 121-131 (2016).
41. Ren, R. et al. Wide-spread whole genome duplications contribute to genome complexity and species diversity in angiosperms. Mol. Plant 18, 30022-30024 (2018).

42. Hegarty, M. J. \& Hiscock, S. J. Genomic clues to the evolutionary success of polyploid plants. Curr. Biol. 18, R435-R444 (2008).

43. McGrath, C. L., Gout, J., Johri, P., Doak, T. G. \& Lynch, M. Differential retention and divergent resolution of duplicate genes following whole-genome duplication. Genome Res. 24, 1665-1675 (2014).

44. Aury, J. M. et al. Global trends of whole-genome duplications revealed by the ciliate Paramecium tetraurelia. Nature 444, 171-178 (2006). 